\title{
Gut anatomy and pH in a Red Sea surgeonfish, Acanthurus nigrofuscus
}

\author{
W. Linn Montgomery, Peggy E. Pollak \\ Department of Biological Sciences, Northern Arizona University, Flagstafí, Arizona 86011, USA
}

\begin{abstract}
Gut length, stomach $\mathrm{pH}$ and intestinal $\mathrm{pH}$ of the brown surgeonfish Acanthurus nigrofuscus change according to conditions of feeding or starvation, time of day, and presence or absence of intestinal protozoan symbionts. Relative gut length declines by 30 to $50 \%$ during short periods of starvation (several hours to ca $2 \mathrm{~d}$ ). Pyloric stomach $\mathrm{pH}$ exceeds that of the cardiac stomach during both daytime feeding periods and night-time resting periods. Fluids in the pyloric caecae are near-neutral (mean $=\mathrm{pH} \mathrm{7.1)}$, exhibit little variation in $\mathrm{pH}$, and appear to buffer intestinal contents. Intestinal $\mathrm{pH}$ rises rapidly from the pyloric sphincter for approximately $35 \%$ of total intestine length, after which $\mathrm{pH}$ drops almost a full $\mathrm{pH}$ unit. This decline in $\mathrm{pH}$ correlates with the presence of large numbers of protozoa, and disappears when the symbionts are eliminated by starvation. The pattern of local differences in $\mathrm{pH}$ within the anterior and middle intestine changes during the night, when symbionts retreat to a bolus of food retained in the posterior intestine. Local differences and short-term changes in stomach or intestinal $\mathrm{pH}$ of herbivorous surgeonfishes may be due to several causes, but they caution against using spot checks of $\mathrm{pH}$ in stomach or intestine as indicators of gut physiology and indicate that we lack in-depth understanding of digestive processes in an ecologically important group of fishes.
\end{abstract}

\section{INTRODŨCTIOON}

Studies of gut anatomy in fishes demonstrate that relative gut length tends to vary with diet, that presence or absence of food influences gut length, and that fishes with stomachs (many families and species possess no discrete stomach) tend to exhibit acidic stomach pH (Suyehiro 1941, Montgomery 1977, Lobel 1981). Few data exist on intestinal $\mathrm{pH}$, except for spot checks which usually document the expected basic medium (Lobel 1981). In addition, there is no consensus on the possible roles of the pyloric caecae, perhaps due to interspecific differences in these functions or to multiple functions within a single species. Functions suggested for caecae include fatty acid oxidation in gouramis (Thyagarajan et al. 1979), lipid absorption in a porgy (Kanazawa et al. 1982), secretion of digestive enzymes in tunas and mullet (Richard et al. 1982, Stevens \& McLeese 1984), absorption of nutrients in tunas (Stevens \& McLeese 1984), provision of habitat for gut microbes (J. N. Grim \& W. L. Montgomery pers. comm.), and secretion of buffers which counteract the high acidity of stomach fluids (this study). Caecal fluids generally exhibit near-neutral or basic $\mathrm{pH}$, and these structures occupy a potentially important position at the junction of stomach with intestine (Thyagarajan et al. 1979, Kanazawa et al. 1982, Richard et al. 1982, Stevens \& McLeese 1984).

During January-February 1987 we studied pH of gut fluid along the entire length of the intestine in a Red Sea surgeonfish, Acanthurus nigrofuscus. We were particularly interested in $\mathrm{pH}$ in relation to presence or absence of an undescribed protozoan which resides within the intestine, as well as to gut anatomy and presence or absence of food (Fishelson et al. 1985a, Montgomery \& Pollak unpubl.). The microbe occurs within all specimens of the brown surgeonfish and occupies a section of the intestine stretching from 35 to $80 \%$ of the distance between the pyloris, at the junction of stomach with intestine, and the anus. A similar protozoan inhabits the intestines of other Acanthurus species in the Red Sea and elsewhere (Fishelson et al. 1985a). In addition to being ultrastructurally distinct from known protozoans (Montgomery \& Pollak unpubl.), this organism represents the first reported case of a consistent intestinal symbiosis in surgeonfishes.

In this article, we demonstrate that significant, localized differences in $\mathrm{pH}$ occur, even within sections of the gut such as stomach and intestine which have historically been treated as if they exhibit little varia- 
tion. The presence of gut microbes, time of day, and conditions of feeding or starvation may exert strong influences on gut $\mathrm{pH}$ regimes.

\section{METHODS}

Studies were performed on brown surgeonfish Acanthurus nigrofuscus inhabiting reefs off the Steinitz Marine Biology Laboratory, Interuniversity Institute, Eilat, Israel (Gulf of Aqaba, Red Sea), during January and February 1987. Specimens were netted after being herded into a monofilament gill net or were taken by hand spear.

We sacrificed fish by a blow to the head and immediately exposed the gut by removing the right wall of the abdominal cavity. Portions of mesenteries of the long, coiled gut were cut to expose sections where $\mathrm{pH}$ was measured with a Microelectrodes Model MI-410 pH probe and a VWR Model $55 \mathrm{pH}$ meter. These measurements were usually begun within 5 to $10 \mathrm{~min}$ and were completed within 15 to $20 \mathrm{~min}$ of sacrifice. After determining $\mathrm{pH}$, we weighed specimens $(\mathrm{g})$ and measured standard length (SL, snout to end of hypural plate) and total intestine length (IL, pyloric sphincter to anus), as well as the distance between the pyloric sphincter and a distinctive, hair-pin loop in the anterior intestine. Diagrams of gut coiling patterns demonstrate that such a loop is characteristic of a variety of surgeonfishes (Jones 1968). Measurements of intestine length were accomplished by cutting the remaining mesenteries and spreading the coils slightly in a fashion that eliminated significant stretching; we estimate that measurements were within $5 \%$ of the actual length within the fish.

We measured $\mathrm{pH}$ at standardized locations within the gut. Initial measurements were taken in the center of the cardiac (anterior) portion of the stomach, the center of the muscular pyloric (posterior) portion of the stomach, and in the distal end of one of the 5 pyloric caecae. Within the intestine, $\mathrm{pH}$ was determined: $1 \mathrm{~cm}$ into the intestine from the pyloric sphincter (junction of stomach with intestine); at $5 \mathrm{~cm}$ intervals from pyloric sphincter to anus; $1 \mathrm{~cm}$ from the anus. Length intervals were used rather than specified fractions of gut length because they could be determined rapidly in guts of varying lengths. For purposes of analysis, we calculated the fraction of intestine length to points where $\mathrm{pH}$ had been measured, and then pooled samples in $10 \%$ length intervals. For example, measurements at 1, 5 and $10 \mathrm{~cm}$ correspond to $2.5,12.5$ and $25 \%$ of a $40 \mathrm{~cm}$ intestine, but $3.3,16.7$ and $33.3 \%$ of a $30 \mathrm{~cm}$ intestine; these data would be pooled in 4 categories $10-9 \%$, $10-19 \%, 20-29 \%, 30-39 \%$ )

Brown surgeonfish fed almost continuously on benthic algae from approximately 07:30 until 16:00 hi at other times they took refuge in nocturnal shelters (Montgomery et al. unpubl.). Fourteen specimens collected during the active feeding period are analyzed separately from a second group of 8 fish which were captured late in the afternoon, transferred to holding tanks, and sampled periodically throughout the night (18:00 to 06:00 h).

In addition, data are presented from several specimens which formed part of a study on the protozoan gut symbiont (Fishelson et al. 1985a, Montgomery \& Pollak unpubl.). Because we do not know whether the effect of this organism is harmful (parasitic), beneficial (mutualistic) or neutral (commensal) with regard to its host, we apply the general and inclusive terms of symbiosis and symbiont to the relationship and the protozoan, respectively. Fish were starved for 2 to $3 \mathrm{~d}$ to induce loss of the symbiont, and then were fed again on natural reef foods in an aquarium, or were tagged with individually numbered plastic disc tags and released within their previous home ranges. Fish not starved but tagged, released and later recaptured during studies conducted in 1983 retained their symbionts. In any event, fish starved and subsequently fed were not reinfected over periods of at least $10 \mathrm{~d}$, although those released in the wild fed actively on normal foods within $1 \mathrm{~d}$ of their release. We measured gut $\mathrm{pH}$ on 2 specimens starved for 2 to $3 \mathrm{~d}$ but not allowed to feed and on 4 specimens starved for 2 to $3 \mathrm{~d}$ and thereafter allowed to feed; all 6 were sacrificed during the day and lacked the symbiont when examined.

\section{RESULTS}

\section{General gut anatomy}

Algae ingested by brown surgeonfish pass into a relatively elongate and thin-walled cardiac portion of the stomach and thence into a moderately muscular (wall ca $3 \mathrm{~mm}$ thick) pyloric region; when the stomach is filled, contents are visible through the wall of the cardiac portion, but not in the pyloric portion. Jones (1968) and Lobel (1981) made similar observations, but termed this type of stomach thin-walled. The stomach of the brown surgeonfish contrasts strongly with the thick-walled (up to ca $1 \mathrm{~cm}$ thick), nearly spherical, grinding structure one finds in other surgeonfishes such as Ctenochaetus spp., some Acanthurus spp., and Prionurus punctatus (Jones 1968, Lobel 1981, Montgomery unpubl., Montgomery et al. unpubl.).

Five pyloric caecae occur at the junction of the pyloric stomach with the intestine, each approximately $1 \mathrm{~cm}$ in length. All are tightly bound by mesenteries to surfaces of the stomach or intestine. 
The intestine is elongate and highly coiled; there is no anatomical differentiation into separate segments. The most distinctive anatomical feature of the intestine is a double coil of the anterior and mid intestine, characteristic of many surgeonfishes (Jones 1968). Immediately posterior to the stomach, the anterior intestine forms a tight coil which terminates in a hairpin loop; a section of the intestine posterior to this loop lies alongside the initial coil and forms the double coil. The loop occurs, on average, $35.3 \%$ of the distance between pyloris and anus, and has special significance in that the undescribed protozoan symbiont noted above rarely occurs anterior to the loop, but occurs in high densities immediately posterior to it (Fishelson et al. $1985 \mathrm{a}$ ).

\section{Gut length}

No seasonal change in intestine length was apparent. Intestine length for 14 fish, 97 to $150 \mathrm{~mm} \mathrm{SL}$, collected during the daytime feeding period in winter 1987 (08:00 to $16: 00 \mathrm{~h})$ ranged from 31 to $45 \mathrm{~cm}(\overline{\mathrm{x}}=38$, $\mathrm{SD}=5)$; relative gut length (IL/SL) averaged $3.0(\mathrm{SD}=$ 0.4 , range 2.5 to 3.9 ). Similar measurements on 20 specimens (100 to $159 \mathrm{~mm} \mathrm{SL}$ ) studied in summer 1983 (Montgomery et al. unpubl.) were: $\mathrm{IL}=30 \mathrm{~cm}(\mathrm{SD}=6$, range 26 to 52 ), IL/SL $=3.0$ (SD 0.4, range 2.1 to 3.6).

Relative intestine length is greater during periods of active feeding (08:00 to $16: 00 \mathrm{~h}$ ) than when fish are not feeding (18:00 to 06:00 h; Table 1 ). The distance to the loop in the intestine declined from $35.3 \%$ in feeding fish to $31.9 \%$ of intestine length in non-feeding fish, suggesting a greater decrease in pyloris-loop length than loop-anus length. This may be due to the fact that food empties last from the posterior intestine and that these surgeonfish retain a bolus of food overnight in the posterior 3 to $5 \mathrm{~cm}$ of intestine, thus distending the posterior intestine.

Surgeonfish intestines were shortened considerably by starvation (Table 1). Fish starved for 2 to $3 \mathrm{~d}$ had intestines half the length $(\mathrm{IL} / \mathrm{SL}=1.4)$ of feeding fish (3.0) and $2 / 3$ the length $(2.3$ ) of non-feeding fish during a nocturnal rest period. Feeding after starvation increased relative intestine length to 1.9 .

\section{Gut $\mathrm{pH}$ during the day}

Brown surgeonfish had acidic stomachs (Table 1). In general, $\mathrm{pH}$ of feeding fish was lower in the cardiac portion of the stomach than the pyloric portion (pairedsample $t$-test: $t=2.88, \mathrm{df}=13, p<0.02$ ), although this pattern did not hold for every individual. Nine of 14 individuals had lower $\mathrm{pH}$ in the cardiac stomach than in the pyloric stomach (differences of 0.2 to $1.8 \mathrm{pH}$ units); the remaining 5 specimens exhibited the inverse or no difference, and differences ranged from 0 to 0.4 $\mathrm{pH}$ units.

Pyloric caecae were consistent in exhibiting basic or near-neutral $\mathrm{pH}$ (range for feeding fish 6.7 to 7.5 ) which exceeded pyloric stomach $\mathrm{pH}$ in all cases (paired-sample $t$-test: $t=5.99, \mathrm{df}=12, p<0.001$; Table 1). Furthermore, variability in caecal $\mathrm{pH}$ was much lower (coefficient of variation, $\mathrm{CV}=64 \%$ ) than for cardiac or pyloric stomach values (184 and $154 \%$, respectively).

Within the first ca $1 \mathrm{~cm}$ of the intestine, $\mathrm{pH}$ values increased from those observed in the adjacent pyloric stomach (5.3) to 7.0 , close to the value (7.1) found in caecae (Fig. 1). From this value, pH rapidly increased to an average of 7.5 at 30 to $39 \%$ of intestine length (IL).

Posterior to this point, intestinal $\mathrm{pH}$ plummeted to levels at least $0.9 \mathrm{pH}$ units less than the value at 30 to $39 \%$ IL. Two factors were associated with this decline: presence of the hair-pin loop and presence of the intestinal symbiont. Average $\mathrm{pH}$ values remained low up to ca $70 \%$ IL, where they began to rise to maximal values (7.7) in the posterior sections of the intestine.

\section{Gut $\mathrm{pH}$ : non-feeding and other conditions}

When feeding was discontinued, gastric pH dropped (Table 1). This was most evident in the cardiac simach, where overnight cessation of feeding calused $\mathrm{pH}$ to decline $1.7 \mathrm{pH}$ units (4.6 to 2.9 ). Variability in pyloric $\mathrm{pH}$ was much higher in fish sampled during the night (CV for cardiac and pyloric stomachs $=133$ and $238 \%$, respectively) than in those taken during the day (184 and $154 \%$ ). There was essentially no change in caecal $\mathrm{pH}$ from day to night (7.1 to 7.0), and caecal $\mathrm{pH}$ variation (CV $=73 \%$ ) was again lower than that of either stomach section.

Fish starved for extended periods appeared to retain the ability to secrete gastric acid, as demonstrated by a mean cardiac stomach $\mathrm{pH}$ of 3.2 for those starved but not subsequently fed (Table 1). When starved fish were fed, however, both cardiac and pyloric stomachs exhibited relatively high $\mathrm{pH}(5.7$ and 6.2 , respectively). Starvation did not appear to affect caecal $\mathrm{pH}$.

The most striking change in intestinal $\mathrm{pH}$ was elimination of the mid-intestinal drop in $\mathrm{pH}$ among starved fish, whether they had been fed subsequently or not. Starvation eliminated the protistan symbiont, and even subsequent feeding by starved fish that were released and observed feeding with schools of wild surgeonfish did not re-establish their gut fauna. Starvation produced no noticeable effects on general gut morphology other than the change in length described above. Thus, 
Table 1. Acanthurus nigrofuscus. Relative intestine length (IL/SL), pH cardiac und pyloric portions of stomach, and pH in pyloric caecae for fish collected January-February 1987 at Eilat, Israel (Gulf of Aqaba, Red Sea). Mean pH measurements were calculated from hydrogen ion concentration ( - antilog $\mathrm{pH}$ ) and then converted back to $\mathrm{pH}$. Coefficients of variation (CV $=$ standard deviation mean $^{-1} 100 \%$ ) were also calculated from hydrogen ion concentrations

\begin{tabular}{|c|c|c|c|c|c|}
\hline Condition & Fish no. & $\mathrm{IL} / \mathrm{SL}$ & $\begin{array}{c}\text { Cardiac } \\
\text { stomach } \mathrm{pH}\end{array}$ & $\begin{array}{c}\text { Pyloric } \\
\text { stomach pH }\end{array}$ & $\begin{array}{c}\text { Caecal } \\
\mathrm{pH}\end{array}$ \\
\hline \multicolumn{6}{|l|}{ Collected } \\
\hline \multirow[t]{16}{*}{$08: 00-16: 00 \mathrm{~h}$} & 1 & 3.4 & 6.0 & 5.9 & 7.5 \\
\hline & 2 & 2.6 & 6.5 & 6.2 & 7.2 \\
\hline & 3 & 3.2 & 5.1 & 4.7 & 7.1 \\
\hline & 4 & 2.5 & 5.3 & 5.5 & 7.5 \\
\hline & 5 & 3.2 & 5.8 & 6.7 & 7.4 \\
\hline & 6 & 2.7 & 5.1 & 6.9 & 7.1 \\
\hline & 7 & 2.7 & 5.3 & 7.0 & - \\
\hline & 8 & 2.8 & 5.5 & 6.6 & 6.7 \\
\hline & 9 & 3.2 & 5.7 & 6.0 & 7.2 \\
\hline & 10 & 3.9 & 6.2 & 5.9 & 6.7 \\
\hline & 11 & 3.5 & 4.6 & 4.6 & 7.0 \\
\hline & 12 & 2.9 & 4.1 & 4.9 & 6.9 \\
\hline & 13 & 3.0 & 4.4 & 6.1 & 7.0 \\
\hline & 14 & $\underline{2.7}$ & $\underline{3.8}$ & 5.1 & 7.4 \\
\hline & Mean $=$ & $\overline{3.0}$ & $\overline{4.6}$ & $\overline{5.3}$ & $\overline{7.1}$ \\
\hline & $\mathrm{CV}=$ & & $184 \%$ & $154 \%$ & $64 \%$ \\
\hline \multicolumn{6}{|l|}{ Collected } \\
\hline \multirow[t]{10}{*}{$18: 00-06: 00 \mathrm{~h}$} & 1 & 2.6 & 2.5 & 2.9 & 7.3 \\
\hline & 2 & 2.3 & 6.7 & 7.0 & 6.9 \\
\hline & 3 & 2.4 & 2.4 & 3.8 & 7.0 \\
\hline & 4 & 2.8 & 3.6 & 5.8 & 7.0 \\
\hline & 5 & 2.3 & 2.8 & 5.9 & 7.4 \\
\hline & 6 & 1.9 & 5.9 & 6.6 & 6.6 \\
\hline & 7 & 2.4 & 3.6 & 4.3 & 7.2 \\
\hline & 8 & $\underline{2.0}$ & $\underline{3.6}$ & $\underline{6.1}$ & 7.4 \\
\hline & Mean $=$ & $\overline{2.3}$ & $\overline{2.9}$ & $\overline{3.7}$ & $\overline{7.0}$ \\
\hline & $\mathrm{CV}=$ & & $133 \%$ & $238 \%$ & $73 \%$ \\
\hline \multirow[t]{4}{*}{ Starved for $48+h$} & 1 & 1.4 & 3.2 & 4.6 & 7.4 \\
\hline & 2 & 1.3 & 3.3 & 6.9 & 7.1 \\
\hline & Mean $=$ & $\overline{1.4}$ & $\overline{3.2}$ & $\overline{4.9}$ & $\overline{7.2}$ \\
\hline & $C V=$ & & $16 \%$ & $140 \%$ & $47 \%$ \\
\hline \multirow[t]{6}{*}{ Starved and fed } & 1 & 2.2 & 5.9 & 7.2 & 7.3 \\
\hline & 2 & 1.8 & 5.2 & 7.0 & 7.1 \\
\hline & 3 & 1.7 & 5.2 & 5.7 & 7.3 \\
\hline & 4 & 1.8 & $\frac{6.5}{-7.5}$ & 7.0 & 7.3 \\
\hline & Mean $=$ & $\overline{1.9}$ & $\overline{5.7}$ & $\overline{6.2}$ & $\overline{7.2}$ \\
\hline & $C V=$ & & $90 \%$ & $169 \%$ & $26 \%$ \\
\hline
\end{tabular}

a distinctive alteration in intestinal $\mathrm{pH}$ appeared to relate directly to large populations of the symbiont. Elsewhere in the gut, where symbionts did not normally occur in large numbers, patterns of $\mathrm{pH}$ change were essentially the same in both feeding and starved fish.

During the night, $\mathrm{pH}$ regimes in the intestine exhibited another pattern (Fig. 1): $\mathrm{pH}$ of the anterior gut was much lower than in feeding or starved fish sampled during the day; $\mathrm{pH}$ of the mid-gut was not as low as in specimens feeding during the day; $\mathrm{pH}$ values in the posterior intestine rose rapidly along the gut to levels equal to daytime maxima. During this time, several changes also occurred in gut contents. First, by 21:00 to 24:00 h, food had been eliminated from virtually the entire intestine. Second, throughout the night a distinctive bolus of food remained in the posterior 3 to $5 \mathrm{~cm}$ of the intestine. Fish in the wild expelled this bolus only after feeding commenced the next morning (Fishelson et al. unpubl.). Third, symbionts were rare in empty portions of the gut but common in the retreating food during the night. Finally, symbionts resided in relatively high densities in the posterior food bolus overnight. 


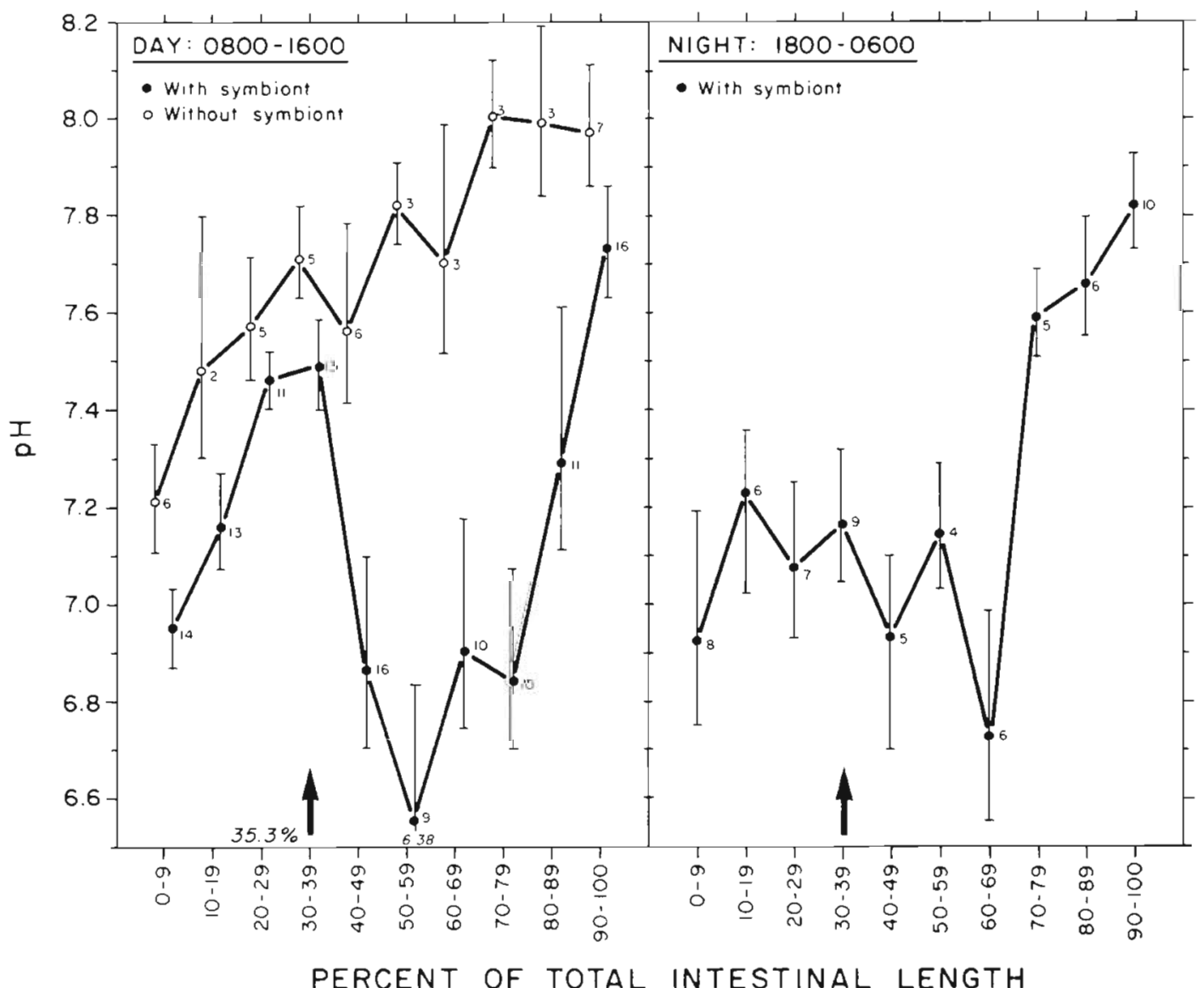

Fig. 1. Acanthurus nigrofuscus. Patterns of intestinal pH among brown surgeonfish during the day (left) and night (right). Means \pm 1 standard error were calculdied from hydrogeñ ion concentrations ( - antilog pH), then transformed to $\mathrm{pH}$ for plotting. Arrow indicates position of the hair-pin loop in the intestine (see text); protozoan symbionts inhabited sections of the gut immediately posterior to the loop. Number of measurements used to calculate individual means is given in the figure; 14 fish provided the daywith-symbiont sample, 6 the day-without-symbiont sample, and 8 the night sample. All specimens sampled at night contained the symbiont discussed in the text

\section{DISCUSSION}

Acanthurus nigrofuscus exemplifies relatively unspecialized, tropical reef herbivores which include various surgeonfishes, damselfishes (Pomacentridae), blennies (Blenniidae), rabbitfishes (Siganidae) and rudderfishes (Kyphosidae). Collectively, such herbivores exert strong and varied influences on reef ecology (Carpenter 1986, Lewis 1986), but the manner in which they process algal foods has received little attention. Like the brown surgeonfish, these fishes feed on a wide range of reef algae, spend large fractions of their time feeding, lack structures specialized for masticating food (such as the pharyngeal tooth mill of parrotfishes, or grinding, gizzard-like stomachs of mullets and some surgeonfishes; review in Lobel 1981), have stomachs with distinct cardiac and pyloric sections containing acidic fluids, and have elongate, coiled intesti- nes that are usually not subdivided into any clear anatomical sections.

Elongate intestines tend to occur together with herbivorous habits in fishes and other vertebrates, perhaps because digestion is enhanced by long residence time for refractory plant foods (Montgomery 1977, Ribble \& Smith 1983). Nevertheless, under different feeding regimes intestine length may change. We do not know if significant or irreversible changes in gut function (passage time for food) or physiology (digestive secretions, assimilation) accompany changes in gut length.

In the brown surgeonfish $\mathrm{pH}$ was lowest in the cardiac portion of the stomach, indicating that acid is secreted here. Measurements of $\mathrm{pH}$ were made on full stomachs of fish which had recently been feeding, and tight packing of algal foods makes any acid flow from pyloric to cardiac sections unlikely. In the absence of 
histological studies, we cannot determine if less acidic conditions in the pyloric than in the cardiac region are due to reduced acid secretion or to the influence of buffers or alkaline media secreted by the pyloric caecae or the stomach itself. As with intestine length, starvation influences stomach function. The relatively high gastric pH in fish which had been starved and subsequently fed suggests that starvation inhibited their ability to secrete gastric acid

A dramatic rise in $\mathrm{pH}$, from a mean for feeding fish of $\mathrm{pH} 5.3$ in the pyloric region to approximately 7.0 in the intestine 1 to $2 \mathrm{~cm}$ away, accompanies the transition from stomach to anterior intestine. We believe this is due to secretions from the pyloric caecae rather than to secretions from the intestine. Values for $\mathrm{pH}$ in the caecae closely match those of the anterior intestine. For example, mean caecal $\mathrm{pH}$ for feeding fish was 7.1 , close to the 7.0 for intestinal $\mathrm{pH}$ and far from the $\mathrm{pH} 5.3$ in the pyloric stomach; similar patterns were found for starved or starved-and-fed fish (caecae 7.2, intestine 7.2, pyloris 4.9 to 6.2 ), and for fish held overnight (7.0, $6.9,3.7$, respectively). All measurements were made in the center of food boli rather than adjacent to the gastric or intestinal walls. We expected that changes in $\mathrm{pH}$ of food materials with movement from stomach to intestine would occur rapidly at the periphery of a bolus but more slowly in the center. Yet within $1 \mathrm{~cm}$ of the pyloric sphincter all food exhibited an alkaline $\mathrm{pH}$ equivalent to that of the pyloric caecae. Mixing of food with alkaline media or buffers appears to be enhanced as small quantities of food pass through the constricted sphincter, adjacent to openings on the caecae.

The physiology of pyloric caecae is poorly known, although at least 3 possible functions have been suggested. First, caecae may assist in digestion, transformation or absorption of lipids and other nutrients (Thyagarajan et al. 1979, Kanazawa et al. 1982, Stevens \& McLeese 1984j. We did not test for digestive or absorptive functions in the brown surgeonfish. Second, caecae may serve as a haven for gut microbes (J. N. Grim \& W. L. Montgomery pers. comm.), although the protozoan symbiont did not occur in the caecae. The caecae of Prionurus punctatus, a surgeonfish from the Gulf of California, Mexico, regularly contain large numbers of a recently described ciliate (Balantidium prionurium Grim, 1985), although the possibility has not been completely eliminated that this may be a pathological condition. Third, caecae may secrete neutralizing fluids or enzymes (Richard et al., 1982, Stevens \& McLeese 1984, this study).

In the brown surgeonfish, it appears that caecae play at least a secretory role. Although we did not test buffering capacity, we suspect that the secretion is a strong buffer rather than simply a basic medium. Secretions from 5 small caecae are sufficient to raise $\mathrm{pH}$ of gut fluids by 1 unit or more in the anterior intestine, to values almost identical with those of the caecae

Once food and fluids enter the intestine, they experience subsequent increases in $\mathrm{pH}$ in the anterior intestine. Only fish sampled at night did not exhibit large increases in $\mathrm{pH}$ of the anterior gut. This could be due to lack of food, with its inherent buffering capacity (note higher $\mathrm{pH}$ in pyloric than cardiac stomach; see Lobel 1981), or to declines in secretion of buffer by the caecae or intestine.

The increase in $\mathrm{pH}$ within the anterior intestine halts as gut contents pass by the hairpin loop, approximately $35 \%$ of the distance along the intestine. After this point there is a sharp drop in $\mathrm{pH}$. When the symbiont is eliminated, this drop does not occur, suggesting that the protozoa generate the local reduction of $\mathrm{pH}$. The impact of lowered $\mathrm{pH}$ on either symbiont or host remains undetermined. We also cannot explain the continued existence of a small reduction in mid-gut $\mathrm{pH}$ among those fish sampled overnight, when the vast majority of symbionts have retreated to the terminal 3 to $5 \mathrm{~cm}(10$ to $15 \%)$ of the intestine.

In the absence of the protozoan, intestinal $\mathrm{pH}$ rises continuously to a maximum of 8.0 in the terminal section of the intestine. Fish with symbionts also have a maximum $\mathrm{pH}$ here, although their average maxima are somewhat lower ( $\mathrm{pH}$ 7.7). Further, in fish retaining protozoa, the terminal section of the gut remains the site of highest $\mathrm{pH}$ overnight, in spite of large numbers of these organisms. This unexpected finding suggests a change in metabolism of the symbiont during nonfeeding periods. Our other studies indicate that this unusual organism shifts from growth and occasional reproductive activity during the day to reproduction with little or no growth at night (Montgomery \& Pollak unpubl.).

Our data describe a physiologically dynamic system in the brown surgeonfish. The gut is subject to greater short-term and local variation than previously recognized in fishes, largely due to the influence of distinct diel cycles of feeding behavior and to metabolism and movements of protozoa resident within the intestine. Additional studies on the brown surgeonfish (Fishelson et al. 1985b, 1987, Montgomery et al. unpubl.) and other reef herbivores (Montgomery 1980, Montgomery \& Gerking 1980, Lobel 1981, Horn \& Neighbors 1984 Lassuy 1984, Horn 1985), provide information about feeding behaviour, selectivity, and some estimates of digestive efficiencies, but generally deal little with specifics of gut physiology, enzymology, or functions of gut symbionts. The paucity of detail on how structurally and biochemically diverse reef algae are digested and assimilated by herbivorous fishes - key transformers of energy and nutrients of reefs - stands in stark contrast to our understanding of many terrestrial herbivores. 
Acknowledgements. Primary support was kindly provided by a grant from the Tobias Landau Foundation for Marine Research; special thanks are due to Mrs Helen Hayes of the Foundation for her assistance and advice. Housing and laboratory facilities in Eilat were provided by the Interuniversity Institute, H. Steinitz Marine Biology Laboratory (Dr Avi Baranes, Resident Director). Faculty and staff of the laboratory were, as always, helpful in many ways. Dr Yehuda Cohen provided equipment, chemicals and space, as well as advice on approaches to these and other studies. Our gracious host in Tel Aviv, Dr Lev Fishelson, provided reagents, aided in collection of fishes, and commented on results. Drs Gary Bateman, Glenn Anderson, Karl Webb and Henry Hooper of Northern Arizona University assisted greatly in preparation for our studies, and the Organized Research and Faculty Development Funds of N.A.U. provided supplemental funding. Comments by Dr Oliver Johnson and 2 anonymous reviewers greatly improved the manuscript.

\section{LITERATURE CITED}

Carpenter, R. C. (1986): Partitioning herbivory and its effects on coral reef algal communities. Ecol. Monogr. 56: 345-363

Fishelson, L., Montgomery, W. L., Myrberg, A. A., Jr (1985a). A unique symbiosis in the gut of tropical herbivorous surgeonfish (Acanthuridae: Teleostei) from the Red Sea Science 229: 49-51

Fishelson, L., Montgomery, W. L., Myrberg, A. A., Jr (1985b) A new fat body associated with the gonad of surgeonfishes (Acanthuridae: Teleostei). Mar Biol. 86: 109-112

Fishelson, L., Montgomery, W. L., Myrberg, A. A., Jr (1987) Biology of surgeonfish Acanthurus nigrofuscus with emphasis on changeover in diet and annual gonadal $c y-$ cles. Mar. Ecol. Prog. Ser. 39: 37-47

Grim, J. N. (1985). Balantidium prionurium n. sp., symbiont in the intestine of the surgeonfish, Prionurus punctatus. J. Protozool. 32: 587-588

Horn, M. H. (1985). Optimal diets in complex environments: feeding strategies of two herbivorous fishes from a temperate intertidal zone. Oecologia (Berl.) 58: 345-350

Horn, M. H., Neighbors, M. A. (1984). Protein and nitrogen. assimilation as a factor in predicting the seasonal macroalgal diet of the monkeyface prickleback. Trans. Am. Fish. Soc. 113: $388-396$
Jones, R. S. (1968). Ecological relationships in Hawaiian and Johnston Island Acanthuridae (surgeonfishes). Micronesica 4: 309-361

Kanazawa, A., Teshima, S., Imatanaka, N., Imada, O., Inoue, A. (1982). Tissue uptake of radioactive eicosapentaenoic acid in the red sea bream. Bull. Jap. Soc scient. Fish 48 : $1441-1444$

Lassuy, D. M. (1984). Diet, intestinal morphology, and nitrogen assimilation efficiency in the damselfish, Stegastes lividus, in Guam. Environ. Biol. Fish. 10: 183-193

Lewis, S. M. (1986). The role of herbivorous fishes in the organization of a Caribbean reef community. Ecol. Monogr. 56: 183-200

Lobel, P. S. (1981). Trophic biology of herbivorous reef fishes: alimentary $\mathrm{pH}$ and digestive capabilities. J. Fish. Biol. 19 365-397

Montgomery, W. L. (1977). Diet and gut morphology in fishes, with special reference to the monkeyface prickleback, Cebidichthys violaceus (Stichaeidae: Blennioidei). Copeia 1977: $178-182$

Montgomery, W. L. (1980). Comparative feeding ecology of two herbivorous damselfishes (Pomacentridae: Teleostei) from the Gulf of California, Mexico. J. exp. mar. Biol. Ecol. 47: $9-24$

Montgomery, W. L., Gerking, S. D. (1980). Marine macroalgae as foods for fishes: an evaluation of potential food quality. Environ. Biol. Fish. 5: 143-153

Ribble, D. O., Smith, M. H. (1983). Relative intestine length and feeding ecology of freshwater fishes. Growth 47 : 292-300

Richard, P. J., Albertini-Berhaut, J., Ceccaldi, H. J. (1982) Evolution de quelques enzymes digestives chez le jeune Mugil capito a diverses etapes de sa croissance. Biochem. Syst. Biol. 10: 185-189

Stevens, E. D., Mcleese, J. M. (1984). Why bluefin tuna have warm tummies: temperature effect on trypsin and chymotrypsin. Am. J. Physiol. 246 (Regulatory İntegrative Comp. Physiol, 15): R487-R494

Suyehiro, Y. (1941). A study of the digestive system and feeding habits of fish. Jap. J. Zool. 10: 1-303

Thyagarajan, K., Sand, D. M., Brockman, H. L., Schlenk, H. (1979). Oxidation of fatty alcohols to acids in the caecum of a gourami (Trichogaster cosby). Biochim. Biophys. Acta 575: $318-326$ 